\title{
SORTING SUBCONTRACTORS' ACTIVITIES IN CONSTRUCTION PROJECTS WITH A NOVEL ADDITIVE-VETO SORTING APPROACH
}

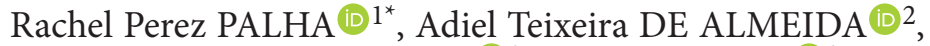 \\ Danielle Costa MORAIS (1)2 ${ }^{2}$, Keith W. HIPEL (1) 3 \\ ${ }^{1}$ Department of Civil and Environmental Engineering, Universidade Federal de Pernambuco,
Av. Acadêmico Hélio Ramos, s/n - Cidade Universitária, Recife, PE, CEP 50.740-530, Brazil
${ }^{2}$ CDSID - Center for Decision Systems and Information Development,
Universidade Federal de Pernambuco, Recife, PE, CEP 50.740-530, Brazil
${ }^{3}$ Department of Systems Design Engineering, University of Waterloo, Waterloo, ON, Canada
}

Received 28 June 2018; accepted 19 February 2019

\begin{abstract}
Selection processes in civil engineering infrastructure projects might require more time and effort than the decisionmakers involved in these projects are normally prepared to devote to running them. A novel approach is proposed to sort these activities into classes that represent their impact on the project, namely additive-veto sorting model, which should be considered before any bidding procedure. Therefore, problems regarding the client's satisfaction caused by subcontractors can be avoided, and the decision-makers involved in the selection problem can devote to each class an effort compatible with the impact that activity might have on the project. The novelty of this method is that it was built to reflect the quasi-compensatory rationality of decision-makers in the construction industry; it provides them with insights on subcontractors' activities, and it is grounded on and inspired by a real case study. The new parameters proposed within this model introduce the idea of vetoing an activity being assigned to a class when this activity is incompatible with the decision-maker's preferences. By using this novel method, the authors succeeded in finding results that avoided a complete compensation amongst the factors considered, taking into account ranges that would be of significant importance in the decision process.
\end{abstract}

Keywords: subcontractor management, multiple criteria analysis, Additive-veto sorting approach, sorting.

\section{Introduction}

Selecting subcontractors in the construction industry is a complex problem that is usually evaluated based on managers' intuition and experience (Biruk, Jaśkowski, \& Czarnigowska, 2017). However, making such selections influences contractors' competitiveness (Tan, Xue, \& Cheung, 2017) and contractors frequently have to make a decision on whether or not to subcontract during the bidding phase (Arditi \& Chotibhongs, 2005). Although this is still an open discussion, this problem has been addressed in the literature for many years since subcontracting activities is a common practice in this industry (Holt, Olomolaiye, \& Harris, 1995). Subcontractor selection is one of the most critical tasks because of the important role that subcontractors play in the success of a project and their impact over the main contractor's competitiveness (Abbasianjahromi, Rajaie, \& Shakeri, 2013).
Selecting and managing subcontractors is a relevant issue since subcontractors account for $80-90 \%$ of the activities performed in a project (Polat, 2016) and they are hired to perform particular activities, which represent different risks to a project and to the decision-makers (DMs) involved in its management. Kumaraswamy and Matthews (2000) discussed the importance of the subcontractor selection process, given the oversupply of specialist firms and the problems that this activity had caused in the construction industry. They advocate that since it is easy to enter this marketplace, these companies have been established with little capital investment and many are unable to function satisfactorily. Therefore, Holt, Olomolaiye, and Harris (1994) and Sönmez, Holt, Yang, and Graham (2002) proposed using prequalification criteria prior to the selection itself in order to avoid issues such as lack of quality, delays,

\footnotetext{
${ }^{*}$ Corresponding author. E-mail: rachelpalha@gmail.com
} 
and additional costs. This approach is enhanced with the methodology proposed in this paper.

The contributions of this paper are as follows: (i) it provides insights for civil engineering and management by addressing the process for selecting subcontractors in the construction industry, bearing in mind that this is an important managerial issue for contractors; (ii) the insights obtained from the real situation studied gave rise to proposing a new model to categorize the activities to be subcontracted, and thus, the DM will be able to apply different selection methodologies for each class; (iii) the authors developed a novel approach to enable a quasi-compensatory evaluation, the additive-veto sorting model; and (iv) to allow the veto, the authors proposed new parameters which are used to veto activities being sorted into classes that are incompatible with the DM's preferences. In a generalization of the model, these activities might be any type of alternatives. The methodological contribution may be applied to any multicriteria decision problem that requires using the concept of veto, which has hitherto only been proposed for non-compensatory rationality. When the DM presents non-compensatory rationality, the preference relation between two alternatives depends only on the subset of criteria that favor the alternatives, irrespective of the differences in the performance of the alternatives for each criterion (Fishburn, 1976). If the DM presents compensatory rationality, this means that by gaining in one variable, a loss in another variable can be compensated for (Munda, 2016). However, when the differences among variables are very large, it is no longer possible to compensate. What is then needed is to use non-compensatory basic indices, which leads to a partially compensatory approach (Martel \& Matarazzo, 2016) which this paper calls a "quasi-compensatory" approach.

An application of this model to a real case situation of a contractor in Brazil is presented. This problem was raised by Palha, de Almeida, and Alencar (2016). However, since there was still room for improvements, the additive-veto model for sorting problematic was proposed. This application considers the same three classes of assignment created in accordance with their criticality, but the model was created to reflect the rationality and correct some misrepresentations of the model previously used in the first phase of the project. This led to a new Multi-Criteria Decision Making/Analysis (MCDM/A) approach being proposed in order to cope with construction management issues that arose within the first phase of the construction of the brewery facility project. This enabled practical construction management and methodological insights to be obtained. Therefore, this allowed managerial implications to be checked by examining the differences in the results which were achieved by using alternative methodologies such as SAW, ROR-UTADIS (Palha et al., 2016), and the novel sorting approach proposed in this article. The insights from this analysis are presented in Section 4 which discusses managerial/practical implications. This showed that, when using all features, better results are achieved from the construction management perspective, there- by revealing a practical situation in which this approach would be required. The method now proposed enables DMs in different contexts to save time and effort on selection processes. Moreover, they find the method easy to understand, because they are used to making trade-offs among objectives during decision processes (Mungle, Benyoucef, Son, \& Tiwari, 2013). They are also used to vetoing bidders that in some way lack the performance needed in some criterion that comes to light during the bidding process (Holt et al., 1995).

This paper offers insights not only into the managerial and subcontracting process, but also a new method which is appropriate for problems related to subcontracting in many other contexts and different kinds of production systems. This article is structured into five sections. An overview of literature is given in Section 2. Section 3 presents the research methodology used in this article. The Additive-veto sorting approach for multicriteria decision problem is presented in Section 4, and in Section 5 an innovative application to the construction industry context is described. Section 6 contains final remarks, draws some conclusions and indicates possible lines of future research studies.

\section{An overview of the literature}

There is a wide range of methodologies that might be used to select subcontractors. Selecting contractors and subcontractors used to be based on tender price alone, but construction clients are becoming more aware that this type of selection is risky and may lead to poor quality and time delay (Singh \& Tiong, 2005) which can be associated with the costs incurred on rework because subcontracting services were unsatisfactory (Love, Edwards, Smith, \& Walker, 2009). In addition, DMs frequently make their decisions based on their experience and without using an evaluation technique (Ulubeyli, Manisali, \& Kazaz, 2010). Thus, Keshavarz Ghorabaee, Amiri, Salehi Sadaghiani, and Hassani Goodarzi (2014) classify this process as a multicriteria problem for which qualitative and quantitative criteria may well be used. Wan and Li (2013) proposed using linear programming for making a multidimensional analysis of preference. This includes using intuitionistic fuzzy sets, trapezoidal fuzzy numbers, intervals, and real numbers to reflect the DM's uncertainty as to his/her preferences

Ng and Skitmore (2014) proposed a framework to evaluate subcontractors by using a balanced scorecard model using ten evaluation criteria. Ballesteros-Perez, Skitmore, Pellicer, and Zhang (2016) analyzed the relationship between the Bid Scoring Formula (BSF) and the competitiveness behavior of bidders in the Spanish construction industry to verify how to control bidder's aggressiveness and avoid problems associated with over-competitiveness. Schöttle and Arroyo (2017) compared three multicriteria methods regarding their performance in the construction industry for which they undertook a sensitivity analysis and a case study. 
Another way to address the problem of outsourcing is to combine AHP (Analytic Hierarchy Process) with PROMETHEE (Preference Ranking Organization Method for Enrichment Evaluations) methods (Polat, 2016) when a non-compensatory approach is required. However, these methodologies were built to evaluate bidders who are taking part in a selection or to verify which criteria DMs take into account when making these evaluations. Therefore, the DMs are subjected to the same level of effort to evaluate any of the activities that need to be subcontracted in a project. Under this assumption, activities that would not influence the contractor's competitiveness are subjected to the same selection procedures as activities that might do so. Thus, sorting the activities according to their impact on the construction would lead to a different outcome.

Within the context of the construction industry, DMs usually think in a way that is more closely associated with compensatory rationality. These DMs acknowledge that on reducing certain costs, the time required to perform an activity may increase and that on improving quality, the project might become more expensive, and so on (Mungle et al., 2013). Therefore they are usually willing to compensate the criteria by conducting trade-offs (Keeney \& Raiffa, 1993). Thus, it would not be suitable to use an outranking method in this context, and therefore this eliminates the possibilities of using ELECTRE-TRI-B (Roy \& Bouyssou, 1993) and PROMSORT (Araz \& Ozkarahan, 2007).

Preference elicitation methods require the DM to specify a range of technical and preferential information so as to calibrate the sorting model. When using a holistic approach, the DM has to assign well-known exemplary alternatives to predefined pre-ordered classes. Based on these assignments the DM's preference information is built using regression-based techniques (Zopounidis \& Doumpos, 2002). The main problem of using a holistic method in this context is that projects greatly vary in size, risk, and the activities involved. In addition, where the project itself is located might change the class of assignment of an activity. Therefore, by applying a holistic method right at the beginning of a project, the DM could present biased preference information, because he/she could evaluate the alternatives based on previous projects that did not relate in any way to the situation faced in the current one. Thus, it is important to consider a method which uses preference elicitation and therefore avoids using DMs' experiences. Instead, their preferences should be used.

The last possibility would be to apply an additive method, such as SAW (Simple Additive Weight). Nevertheless, problems of an unbalanced set of alternatives might arise. This occurs when an alternative has a top performance in one or more criteria but a very low one in others. Thus, the compensation that can arise under this method might be undesirable at certain levels. This same problem might occur when using AHPSort (Ishizaka, Pearman, \& Nemery, 2012) or TOPSIS-Sort (Sabokbar, Hosseini, Banaitis, \& Banaitiene, 2016) because these methods are fully compensatory. The veto concept would be an alternative way to address the issue of an unbalanced set of alternatives. Al- though the veto concept is traditionally linked to the outranking approaches, it has been used by de Almeida (2013) in the additive model for choice and ranking problems.

According to Vetschera, Chen, Hipel, and Kilgour (2010), sorting problems are significantly different from choice or ranking ones as they need proper parametrization and the use of specific methods. Therefore, ranking methods might be adapted to sorting problems by considering proper parametrization (Ishizaka et al., 2012), since the assignment of an alternative to a class includes describing it and incorporates preference information that can be used by the DM (Doumpos \& Zopounidis, 2004). Thus the meaning to be given to an alternative is linked to the class to which it belongs.

This gap in the literature is filled by the novel MCDM approach proposed in Section 3. It adds the possibility of using the veto concept for additive sorting problems, thereby enabling a quasi-compensatory approach. This approach lets issues be dealt with that arise from an unbalanced set of alternatives. What prompted considering it was a real-world situation observed in a civil engineering managerial process and a case study associated with it. Thus, Section 3 presents the Additive-veto sorting approach with a preference elicitation method, thus extending the additive-veto for ranking proposed by de Almeida (2013) to sorting problems. It does so by considering a new set of parameters and novel decision rules to introduce the idea of vetoing the classification of an alternative when assigning it to a class profile.

\section{Research methodology}

This study was built as the development of prior research presented by Palha et al. (2016) and following the MCDM/A framework presented by de Almeida et al. (2015), taking into consideration the methodological steps for structuring and solving an MCDM/A problem. Throughout this methodological framework, methods are defined that fit the DMs' preferences and which can include compensatory or non-compensatory rationality and the characteristics of the problem, such as types of activities, risks, and contract sizes.

Based on this particular problem, it has been developed and applied the novel MCDM method proposed in this paper, enabling to test the novel approach to compare and analyze its results with those presented by Palha et al. (2016) when using ROR UTADIS (Kadziński, Ciomek, \& Słowiński, 2015).

The study by Palha et al. (2016) concerned the construction of a brewery in the State of Pernambuco in Northeast Brazil which was designed to have a productive capacity of 600 million liters of beer per year. The plant consists of 19 buildings, of which 15 are industrial, and the site covers an area of $297,000 \mathrm{~m}^{2}$. The expected cost of this construction was US\$ 70 million. It was a cost-plus contract, which led the contractor to subcontract most of the activities. This required more attention to be paid to the process for selecting sub-contractors throughout the 
project. In addition, in case of liabilities, both the contractor and the owner of the brewery will be prosecuted. This means that satisfying this client relies not only on developing the project itself but also on avoiding penalty charges being incurred. In the context of this project, the Director of the Construction (DC) is the DM and is responsible for the project, both legally and to the contractor.

It took a long time to construct the brewery, and this took place over two phases. This allowed the DM to revisit her preferences and re-evaluate the data. In the period of this research, several changes occurred in the civil engineering market in Brazil, which prompted the DM to feel uncomfortable about providing preference information based on holistic assignments. In addition, after the first sorting interaction, the DM verified when selecting suppliers that some of the sorting assignments were incompatible with the impact on the owner, the contractor and the project itself of subcontracting the activity. Thus, the project required a new method to be developed for which preference elicitation could be used and which was, at least partially, compensatory. The method developed was the Additive-veto sorting approach for multicriteria decision problems. This was created based on this problem, but it might be used in other sorting problems as well. Therefore, each decision is affected by the DM's style and problem context. Thus, there will be situations where a fully compensatory or a non-compensatory approach may be required, and also, situations where an intermediate kind of approach would be more suitable, and which would, therefore, require a "quasi-compensatory" one. The approach presented in Section 3 was tested in the construction of the brewery where the problem arose for which a hypothetical-deductive research method validated similarly as in Polat (2016) and Abbasianjahromi, Rajaie, Shakeri, and Kazemi (2016), based on the validity of the assumption of the study.

\section{The Additive-veto sorting approach for multicriteria decision problems}

Using the veto concept does not permit an alternative to be sorted when based only on its overall value, but this must also consider restrictions that the DM has included in his/her quasi-compensatory preference information. Therefore, parametric information, such as the profiles of classes and the upper and lower thresholds are elicited from the DM and considered with two veto conditions: the criterion veto index, and the criteria weight coalition veto.

The procedure presented considers three steps. Figure 1 presents how the first two steps are conducted. First, the global value of the alternatives and profiles are calculated, and the alternatives are analysed in order to determine the class assignments. Secondly, decision rules are applied to the alternatives to veto their classification to classes of assignment. After the analysis is completed, a recommendation is presented to the DM, after which he/ she can review his/her preference information and run a sensitivity analysis.

\subsection{Evaluation of alternatives and profiles}

The first step of this approach consists of determining the overall value of the alternatives and specifying the profile for each class. This value is calculated using Eqn (1). Thus, the scale constants must be elicited from the DM, using the trade-off method (Keeney \& Raiffa, 1993). Consider a finite set of $m$ alternatives, $A=\left\{x_{1}, x_{2}, \ldots, x_{m}\right\}$, which is evaluated using a finite set $g=\left\{g_{1}, g_{2}, \ldots, g_{n}\right\}$ of $n$ evaluation criteria. In the context of the additive-veto model for sorting problems, the criteria are the ordinal descriptions of an alternative (Zopounidis \& Doumpos, 2002). The classes describe the alternatives, and in sorting problems, they also incorporate preferential information from a decision making context, unlike what happens in classification methods, where the classes describe the alternatives in a nominal way (Zopounidis \& Doumpos, 2002). In terms of the selection problem that gave rise to the method, the criteria are the characteristics that each activity might have and that can be used to evaluate their impact over the project, while the alternatives are the activities that will be subcontracted and the classes represent the impact that an alternative might have over the project and are used to define how the project should manage the selection process and the subcontractor:

$$
V\left(x_{j}\right)=\sum_{i=1}^{n} k_{i} v_{i}\left(x_{j}\right)
$$

where $V\left(x_{j}\right)$ is the overall value of alternative $x_{j} ; k_{i}$ is the scale constant of criterion $i$ and $\sum_{i=1}^{n} k_{i}=1 ; v_{i}\left(x_{j}\right)$ is the value of the consequence of criterion $i$.

The value of the consequence, $v_{i}\left(x_{j}\right)$, is a function that represents the value of an alternative $j$ on the attribute $i$. The shape of this function and its parameters are obtained by using an elicitation process with the DM. Thus, $v_{i}\left(x_{j}\right)$ may be a linear or non-linear function (Keeney \& Raiffa, 1993).

The set of alternatives sometimes consists of alternatives, which have a high performance in one criterion and a low performance in another, to such an extent that these low performances are fully compensated for by the higher ones. Even though the idea of the additive method is to allow this compensation, sometimes the value of the alternative in one criterion is well above an acceptable level, thereby making it necessary to eliminate that evaluation or limit its effect. In order to provide balance to the set of alternatives and to avoid possible misclassification, a veto condition is proposed.

For sorting problems, there are two ways to introduce the veto concept. First, in one approach, an alternative assigned to a specific class can be vetoed, in which case it is sorted to a more appropriate lower class. In a second procedure, the performance of the alternative could be penalized as described in Eqn (3) and thereby be assigned to a suitable lower class. This veto condition was presented by de Almeida (2013) for ranking problems and, in this 


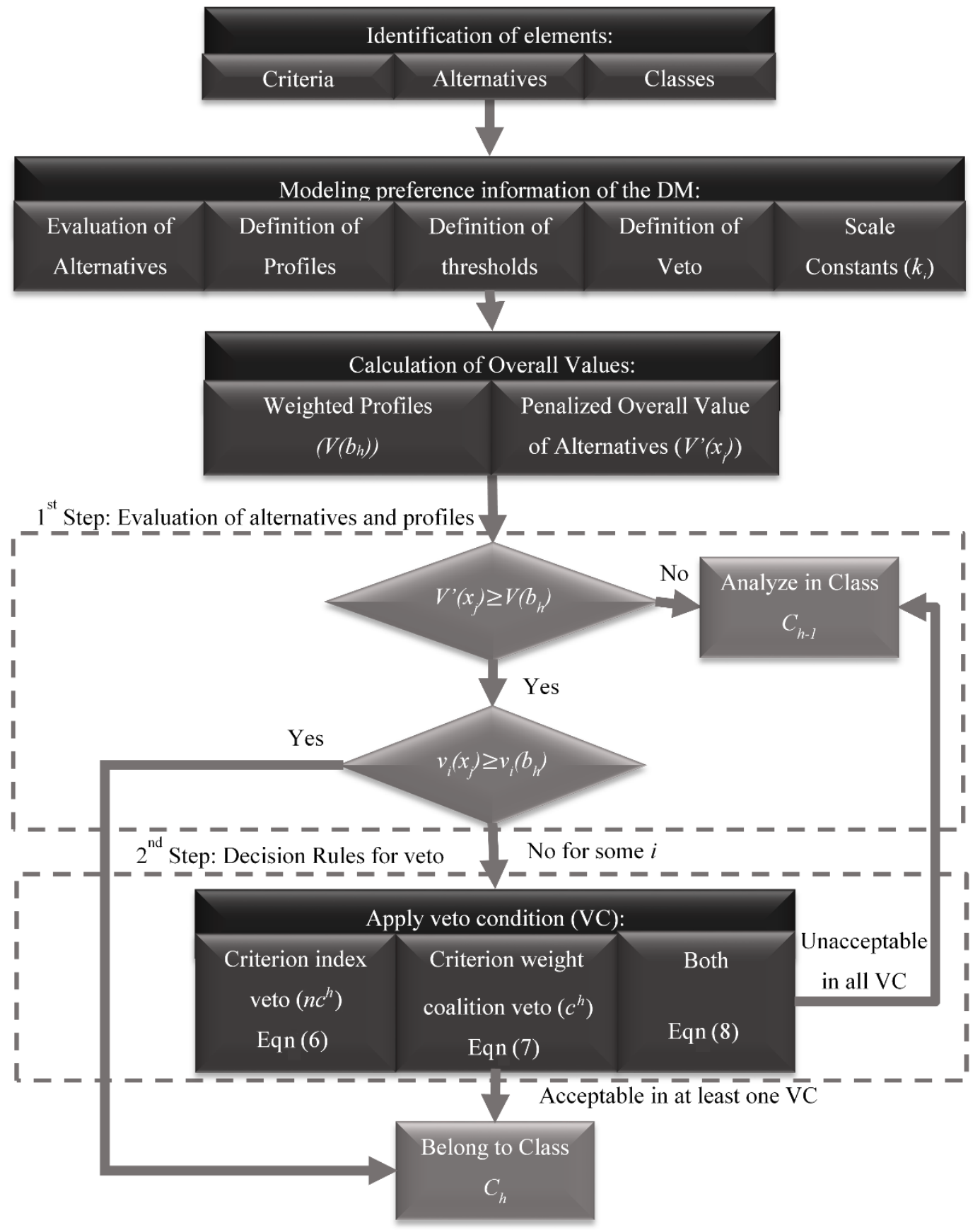

Figure 1. The Additive-veto sorting approach

model, it is applied in the first step as a penalty by using Eqns (2) and (3) across the overall value of the alternatives.

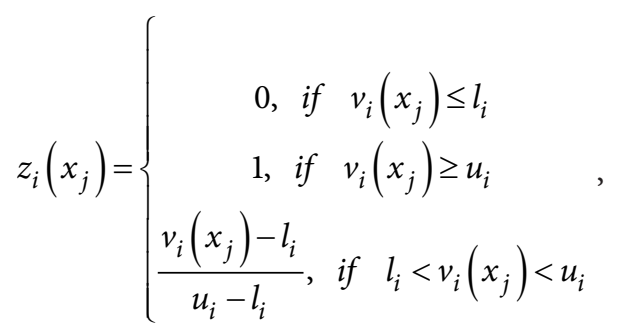

where $z_{i}\left(x_{j}\right)$ is the penalization function of alternative $x_{j}$ for criterion $i ; u_{i}$ is the upper threshold for criterion $i$; $l_{i}$ is the lower threshold for criterion $i$.

$$
V^{\prime}\left(x_{j}\right)=r\left(x_{j}\right) \sum_{i=1}^{n} k_{i} v_{i}\left(x_{j}\right),
$$

where $V^{\prime}\left(x_{j}\right)$ is the penalized global function of alternative $x_{j} ; r\left(x_{j}\right)$ is the penalization index of alternative $x_{j}$, where $r\left(x_{j}\right)=\sum_{i=1}^{n} r_{i}\left(x_{j}\right) ; r_{i}\left(x_{j}\right)$ is the weighted penalization function for alternative $x_{j}$, where $r_{i}\left(x_{j}\right)=z_{i}\left(x_{j}\right) k_{i}$.

The upper threshold $\left(u_{i}\right)$ is the minimum acceptable value of performance for criterion $i$ for any alternative below which the DM believes a penalization must be used in the overall value of that alternative; whereas the lower threshold $\left(l_{i}\right)$ is the maximum value of criterion $i$ for which the performance of the alternative starts to be unaccept- 
able. Therefore, that criterion should not contribute to calculating the overall value of the alternative (de Almeida, 2013). The DM must provide both parameters. Additionally, whenever the DM does not wish to introduce the penalization in a criterion, both thresholds must be set to the minimum value in the scale.

Let $C_{h}$, be $q$ predefined preference-ordered classes in such a way that $C_{q} \succ C_{q-1} \succ \ldots \succ C_{2} \succ C_{1}$. The assignment of an alternative to a class is conducted by comparing an alternative with the reference alternative of the class under consideration. The profile is the reference alternative that is the boundary between two classes (Doumpos \& Zopounidis, 2004). Thus, $b_{h}$ is the vector of the performance of this reference alternative with respect to each criterion and represents the limit between class $C_{h}$ and class $C_{h+1}$ (Roy $\&$ Bouyssou, 1993). The threshold of a class or limit profile is the overall value of its reference alternative, which is calculated using equation $V\left(b_{h}\right)=\sum_{i=1}^{n} k_{i} v_{i}\left(b_{h}\right)$. The threshold is specified with $v_{i}\left(b_{h}\right)$ for each criterion and aggregated with the formulation given above for $V\left(b_{h}\right)$. When using the proposed approach, the analyst should consider that the limit profiles of each category have been defined prior to defining the veto parameters. Thus, as the veto parameters are a function of the values set for the profile boundaries, these would not work to veto the reference alternative, and therefore would prevent further inconsistencies.

The model presented is divided into a global and a local analysis. The main idea of the global analysis is to compare the penalized global value of each alternative $x_{j}$ $\left(V^{\prime}\left(x_{j}\right)\right)$ with the limit profile $V\left(b_{h}\right)$ and to state whether or not the alternative can belong to class $h$. When it cannot, then it is compared to lower classes until a suitable class is found. When the alternative might belong to class $h$, the appropriateness of this classification must be verified. This comparison is carried out by using the following rule presented in Eqn (4):

$$
\left\{\begin{array}{l}
x_{j} \in A, \quad j=1, \ldots, m ; \quad h=q, \ldots, 1 \\
\text { if } V^{\prime}\left(x_{j}\right) \geq V\left(b_{h}\right) \text { then } x_{j} \in P_{h} \\
\text { if } V^{\prime}\left(x_{j}\right)<V\left(b_{h}\right) \text { then } x_{j} \notin P_{h}
\end{array}\right.
$$

where $P_{h}$ is the subset of $A$ that might belong to class $C_{h}$.

Every alternative has to be assigned to one class, and, since Class $C_{1}$ is the worst possible class, if one alternative cannot be assigned to any other class, it will be assigned to Class $C_{1}$. Therefore, for $h=1, V\left(b_{1}\right)=0$. The verification of the suitability of an alternative to a class occurs only over the alternatives belonging to $P_{h}$. This will be further verified to confirm whether or not the alternative belongs to Class $C_{h}$, and depends on the local analysis.

In the local analysis, the performance of the alternatives belonging to subset $P_{h}$, are compared with that of the reference alternative $b_{h}$. This analysis is the last analysis of the first step, namely, to confirm if the alternative belongs to class $C_{h}$ or if it is necessary to use the second step. Eqn (5) presents the rule for the second filter of the model. If the alternative is at least as good as the reference alternative for class $C_{h}$, then it certainly belongs to it. If in at least one criterion the alternative fails, then the procedure moves on to the second step.

$$
\left\{\begin{array}{c}
\forall x_{j} \in P_{h}, \quad j=1, \ldots, m, i=1, \ldots, n, h=1, \ldots, q \\
\text { if } v_{1}\left(x_{j}\right) \geq v_{1}\left(b_{h}\right) \wedge v_{2}\left(x_{j}\right) \geq v_{2}\left(b_{h}\right) \wedge \ldots \wedge v_{n}\left(x_{j}\right) \geq v_{n}\left(b_{h}\right) \text { then } x_{j} \in C_{h} . \\
\text { if } v_{i}\left(x_{j}\right)<v_{i}\left(b_{h}\right) \text { for some } i \text { then apply decision rule for veto }
\end{array}\right.
$$

\subsection{Decision rule for veto in the sorting problems}

The idea of using a veto is currently being used in noncompensatory methods, such as in ELECTRE, and has been adapted for use with some compensatory methods, such as the Additive-veto model for choice and ranking problems (de Almeida, 2013) and the TOPSIS (Technique for Order Preference by Similarity to Ideal Solution) method (Kelemenis \& Askounis, 2010). The veto condition has also been used in the context of group decision by using a veto function based on the principles of social choices (Moulin, 1981), and with the Additive Model (Aguayo, Mateos, \& Jiménez, 2014; Sabio, Jiménez-Martín, \& Mateos, 2015), as well as in the context of negotiation, by vetoing possible solutions (Filzmoser \& Gettinger, 2013) or by scoring negotiation offers with TOPSIS (Wachowicz \& Blaszczyk, 2013) and fuzzy-TOPSIS (Roszkowska \& Wachowicz, 2015).

In the Additive-veto model for ranking problems, the veto rejects an alternative from its original ranking posi- tion (de Almeida, 2013). Bregar (2018) proposed an approach similar to the additive-veto model for ranking which was associated with the ELECTRE sorting rules. This enabled incomparability to be considered present in the problem model. The novel approach presented in this paper proposes new decision rules that allow the alternatives to be sorted into classes and all alternatives have to be sorted in one unique class with a different set of parameters and does not enable incomparability. In TOPSIS, the veto condition expresses the rejection of an alternative as a solution. In the proposed model, the role of the veto is to reject the alternative as a solution for that specific class and direct the analysis to another class to reach a final recommendation.

The second step consists of determining if the alternatives belonging to subset $P_{h}$ must belong to class $C_{h}$. Therefore, two other analyses have to be carried out, whereby one is local and the other global. The criteria weight coalition veto $\left(c^{h}\right)$ provides a global veto and the criterion veto index $\left(n c^{h}\right)$, a local one. These veto conditions are 
presented in Definitions 1 and 2. These two parameters can be used either separately or combined. When a definition should be used depends on the context of the problem and the DM's preference structure.

Definition 1. The criterion veto index $\left(n c^{h}\right)$ is a value that reflects preference information provided by the DM such that the performance of the alternatives cannot be below the performance of the reference alternative in $h-n c^{h}$ classes below it. For instance, if $n c^{h}$ is 2 for the fourth class, its performance in any criterion cannot be less than that expected for the second class. Hence, if the alternative has an overall value compatible with the fourth class but in some criterion, its performance is lower than the reference alternative of class two, the alternative has to be analyzed in class three. In this case, the DM in the construction industry would believe that the activity should be placed in a lower class if by comparing it with $n c^{h}$ classes below class $C_{h}$, the alternative does not outperform this profile. The local veto analysis is given in Eqn (6) and is based on Definition 1 , by considering the criterion veto index as a measure of vetoing the alternative to be assigned to some class $h$.

$$
\left\{\begin{array}{c}
\forall x_{j} \in P_{h}, n c^{h} \in \mathbb{N}^{+}, j=1, \ldots, m, i=1, \ldots, n, h=2, \ldots, q, n c^{h}=0, \ldots, q-1 \\
\text { if } h>2\left\{\begin{array}{c}
\text { if } v_{i}\left(x_{j}\right) \geq v_{i}\left(b_{h-n c^{h}}\right) \forall i, \text { then } x_{j} \in C_{h} \\
\text { if } v_{i}\left(x_{j}\right)<v_{i}\left(b_{h-n c^{h}}\right) \text { for some } i, \text { then } x_{j} \notin C_{h}
\end{array}\right. \\
\text { if } h=2\left\{\begin{array}{c}
\text { if } v_{i}\left(x_{j}\right) \geq v_{i}\left(\theta_{i}\left(b_{2}-b_{1}\right)+b_{1}\right) \forall i, \text { then } x_{j} \in C_{2} \\
\text { if } v_{i}\left(x_{j}\right)<v_{i}\left(\theta_{i}\left(b_{2}-b_{1}\right)+b_{1}\right) \text { for some } i, \text { then } x_{j} \notin C_{2} \\
\text { if } h=1, n c^{h}=0
\end{array}\right.
\end{array}\right.
$$

where $\theta_{i}$ is the criteria veto index threshold for criterion $i$ provided by the DM based on the range between profiles $b_{2}$ and $b_{1}$. This parameter is presented as a percentage and, the DM might decide to not use this component, setting it to zero, thus forcing the comparison to match the worst possible class. An aspect that is important to clarify is that $v_{i}\left(b_{1}\right)$ is not zero. The values presented for this profile are the least preferable values in each criterion.

This index consists of comparing the performance of all criteria that should belong to Class $C_{h}$, with the performance of a number of classes below it, defined by the criterion veto index. This analysis offers the DM flexibility and the idea is that even though the overall value is greater than $V\left(b_{h}\right)$, individually the criteria did not confirm the assignment. As a quasi-compensatory procedure, one criterion should compensate for the other, so the DM decides up to what limit this compensation is acceptable, which means that this compensation is acceptable if all criteria are at least as good as the one acceptable for $n c^{h}$ classes below it. This veto analysis has no meaning for alternatives sorted in class $C_{1}$, because they are the alternatives that were not sorted in any other class, meaning they could not be sorted in any class below this one. Therefore, for class $C_{1}$ this index is zero. In addition, this proposition does not take into account median profiles, only boundaries. Therefore, $n c^{h}$ has to be positive and integer to make the comparison feasible. Also, the DM might decide not to use this condition; in that case, he/she must define the criterion veto index as one class below the class of analysis, $h$, and, thus, all $v_{i}\left(b_{h-n c^{h}}\right)$ will be the profile of class $C_{1}$ to all criteria, thereby disabling the veto condition associated with this index. By relaxing it completely, all criteria are to be compared with the least preferable profile.
Definition 2. The criterion weight coalition veto $\left(c^{h}\right)$ is the lower limit of the sum of the scale constants of the criteria whose performance is at least as good as the one required for the class of analysis that allows an alternative to be assigned to that group. This preference condition disallows assigning an alternative to Class $C_{h}$ whenever the number of criteria with a performance lower than the limit profile is weighted, and the result is lower than $c^{h}$.

For the approach presented in Definition 2, the DM can easily interpret the outcomes for all criteria and can detect low performances for a given criterion; which level is undesirable and which requires a veto. However, this concept for veto is not related to a direct change of classification of that alternative. Rather, it is a verification of how many criteria the alternative has to fail before it starts to be unacceptable to assign it into the class under consideration. The DM needs this approach when he/she is not willing to compare the alternatives with several different classes. In this case, the DM in the construction industry would believe that the activity should be placed in a lower class if a percentage of the criteria that he/she considers is relevant, is not compatible with the class under analysis. Eqn (7) presents the rule that uses the criteria weight coalition veto:

$$
\left\{\begin{array}{l}
\forall x_{j} \in P_{h} \quad j=1, \ldots, m, i=1, \ldots, n, h=1, \ldots, q, \\
\text { if } \sum_{i \in v_{i}\left(x_{j}\right) \geq v_{i}\left(b_{h}\right)} k_{i} \geq c^{h} \text { then } x_{j} \in C_{h} \\
\text { if } \sum_{i \in v_{i}\left(x_{j}\right) \geq v_{i}\left(b_{h}\right)} k_{i}<c^{h} \text { then } x_{j} \notin C_{h}
\end{array}\right.
$$

where: $k_{i}$ is the scale constant of criterion $i$ and $\sum_{i=1}^{n} k_{i}=1$;

$P_{h}$ is the subset of $A$ that might belong to the class $C_{h}$; $c^{h}$ is the weight coalition veto informed by the DM. 
The weight coalition index consists of summing up all the scale constants of the criteria that achieve a performance better than the one required for the class being considered. If the DM decides not to apply this veto condition to disable this parameter, the criteria weight coalition veto has to be parametrized as zero. Hence, any value found for the criteria weight coalition will be greater than its veto.

Besides the two foregoing approaches, the DM may believe that they must be combined. In this case, the activity should be sorted into a lower class if at least a percentage of the criteria is compatible with that class, and this is not sufficient for the assignment since the DM wants to compare the performance of the alternative with classes below the class of assignment. Whenever this is the situation, the DM has to provide both veto indices. This analysis is made by considering both cases as presented in Eqn (8), which is more restrictive than the previous two since the alternative has to overcome both conditions:

$$
\left\{\begin{array}{c}
\forall x_{j} \in P_{h}, n c^{h} \in \mathbb{N}^{+}, j=1, \ldots, m, i=1, \ldots, n, h=2, \ldots, q, n c^{h}=0, \ldots, q-1 \\
\text { if } h>2\left\{\begin{array}{r}
\quad \text { if } \sum_{i \in v_{i}\left(x_{j}\right) \geq v_{i}\left(b_{h}\right)} k_{i} \geq c^{h} \wedge v_{i}\left(x_{j}\right) \geq v_{i}\left(b_{h-n c^{h}}\right) \forall i, \text { then } x_{j} \in C_{h} \\
\text { if } \sum_{i \in v_{i}\left(x_{j}\right) \geq v_{i}\left(b_{h}\right)} k_{i}<c^{h} \vee v_{i}\left(x_{j}\right)<v_{i}\left(b_{h-n c^{h}}\right) \text { for some } i, \text { then } x_{j} \notin C_{h}
\end{array}\right. \\
\text { if } h=2\left\{\begin{array}{c}
\text { if } \sum_{i \in v_{i}\left(x_{j}\right) \geq v_{i}\left(b_{h}\right)} k_{i} \geq c^{h} \wedge v_{i}\left(x_{j}\right) \geq v_{i}\left(\theta_{i}\left(b_{2}-b_{1}\right)+b_{1}\right) \forall i, \text { then } x_{j} \in C_{2} \\
\text { if } \sum_{i \in v_{i}\left(x_{j}\right) \geq v_{i}\left(b_{h}\right)} k_{i}<c^{h} \vee \\
v_{i}\left(x_{j}\right)<v_{i}\left(\theta_{i}\left(b_{2}-b_{1}\right)+b_{1}\right) \text { for some } i \text {, then } x_{j} \notin C_{2} \\
\text { if } h=1, n c^{h}=0
\end{array}\right.
\end{array}\right.
$$

\subsection{Recommendation and sensitivity analysis}

The evaluation ends with the third step, which consists of making a recommendation to the DM based on conducting Steps 1 and 2 and taking the DM's preference information into consideration. To verify the robustness of the recommendation, it is important to conduct a sensitivity analysis of all parameters since this might bring some degree of hesitation to the solution if the results are sensitive to small modifications. Sensitivity Analysis (SA) can be carried out by using a Monte Carlo simulation on model parameters, such as scaling constants and limit profiles in order to verify, if on using different parameter values, how likely it would be for alternatives to change classes by considering all the veto parameters that the DM has provided. SA has to be conducted using whichever parameters the DM does not feel comfortable about. Moreover, it is important to determine if, by introducing any modification to the set of parameters, this would cause significant changes to the recommendation. The model might be sensitive to modifications to either the criteria weight coali- tion index or the criterion veto index. There are different approaches available in the literature for global SA (Iooss \& Lemaitre, 2015) and therefore for verifying robustness. When using a Monte Carlo Simulation, the analysis may consider all parameters at the same time or a subset of parameters. Since parameter ranges are considered for simulation, the sensitivity for each parameter may be verified using a uniform or triangular distribution (Medeiros, Alencar, \& de Almeida, 2017).

\section{Sorting activities in the heavy construction context}

The model was developed to reflect the DM's rationality and to correct some misrepresentations of the model used in the first phase of the project, reported in Palha et al. (2016). The criteria were determined by considering the DC's objectives regarding the problem and are presented and explained in Table 1, which considers data from different sources on the assessment of each criterion in a given scale. The project had over thirty activities to

Table 1. Criteria used to analyze the activities of the construction of the brewery (adapted from Palha et al., 2016)

\begin{tabular}{|l|l|c|c|}
\hline \multicolumn{1}{|c|}{ Criteria } & \multicolumn{1}{|c|}{ Description } & Scale & Min/Max \\
\hline Cost $\left(g_{1}\right)$ & The budget to conduct the activity. & Monetary & Max \\
\hline Duration of activity $\left(g_{2}\right)$ & Time expected to complete the activity. & Days & Max \\
\hline Number of suppliers $\left(g_{3}\right)$ & The number of suppliers available in nearby markets. & Min \\
\hline Available resources $\left(g_{4}\right)$ & $\begin{array}{l}\text { Availability of resources, such as labor, equipment, and } \\
\text { material in the neighborhood }\end{array}$ & Qualitative (1 to 5) & Min \\
\hline Exposure to risk $\left(g_{5}\right)$ & $\begin{array}{l}\text { Exposure to risk related to technical responsibility and } \\
\text { permanence of labor on the construction site. }\end{array}$ & Qualitative (1 to 5) & Max \\
\hline Need for maintenance $\left(g_{6}\right)$ & Evaluation of the need for maintenance to attain the activity. & Qualitative (1 to 4) & Max \\
\hline Interaction with other activities $\left(g_{7}\right)$ & $\begin{array}{l}\text { Proxy attribute to take into account possible impact from the } \\
\text { activity on other activities regarding security risks and duration. }\end{array}$ & Qualitative (1 to 5) & Max \\
\hline
\end{tabular}


Table 2. Evaluation matrix of the activities considered (adapted from Palha et al., 2016)

\begin{tabular}{|l|c|c|c|c|c|c|c|}
\hline \multirow{2}{*}{\multicolumn{1}{|c|}{ Description }} & \multicolumn{9}{c|}{ Criteria } \\
\cline { 2 - 8 } & $g_{1}$ & $g_{2}$ & $g_{3}$ & $g_{4}$ & $g_{5}$ & $g_{6}$ & $g_{7}$ \\
\hline Air conditioning & $70,000.00$ & 90.00 & 3.00 & 3.00 & 3.00 & 1.00 & 3.00 \\
\hline Asphalt paving & $90,000.00$ & 4.00 & 2.00 & 5.00 & 5.00 & 4.00 & 2.00 \\
\hline Concrete & $4,000,000.00$ & 360.00 & 5.00 & 3.00 & 5.00 & 4.00 & 5.00 \\
\hline Concrete paving & $700,000.00$ & 60.00 & 4.00 & 1.00 & 5.00 & 4.00 & 5.00 \\
\hline Containers & $370,000.00$ & 360.00 & 5.00 & 1.00 & 1.00 & 1.00 & 1.00 \\
\hline Continuous flight auger (CFA) stake & $700,000.00$ & 180.00 & 12.00 & 1.00 & 5.00 & 4.00 & 4.00 \\
\hline Earthworks & $1,800,000.00$ & 90.00 & 6.00 & 5.00 & 5.00 & 4.00 & 5.00 \\
\hline Food supply & $1,200,000.00$ & 360.00 & 5.00 & 2.00 & 3.00 & 1.00 & 3.00 \\
\hline Gypsum liner & $35,000.00$ & 21.00 & 2.00 & 1.00 & 5.00 & 1.00 & 2.00 \\
\hline Heavy equipment & $400,000.00$ & 360.00 & 6.00 & 4.00 & 3.00 & 3.00 & 5.00 \\
\hline Hydroseeding & $110,000.00$ & 15.00 & 2.00 & 1.00 & 5.00 & 4.00 & 2.00 \\
\hline Molds, shoring and scaffolding & $150,000.00$ & 360.00 & 4.00 & 4.00 & 5.00 & 1.00 & 5.00 \\
\hline Precast concrete & $2,700,000.00$ & 270.00 & 2.00 & 5.00 & 4.00 & 1.00 & 4.00 \\
\hline Security of property & $500,000.00$ & 360.00 & 4.00 & 5.00 & 3.00 & 1.00 & 3.00 \\
\hline Transport of personnel & $1,500,000.00$ & 360.00 & 4.00 & 5.00 & 3.00 & 4.00 & 3.00 \\
\hline Suppression of vegetation & $19,000.00$ & 15.00 & 1.00 & 5.00 & 5.00 & 1.00 & 4.00 \\
\hline Waterproofing & $25,000.00$ & 60.00 & 2.00 & 5.00 & 5.00 & 1.00 & 2.00 \\
\hline
\end{tabular}

be subcontracted, but to simplify matters, only seventeen were considered under this analysis. All values presented in Table 2 are real and were used to evaluate the activities. Since the intention of sorting the activities into classes is to minimize the time and effort required from DMs to select subcontractors, the criteria are evaluated considering that the worst situation should be sorted in the topranked class while the best situation, which would require less commitment from the DMs in the decision process, should be sorted in bottom-ranked classes. Therefore, one might think that the criterion of cost, for example, should be minimized, but this would lead to costly activities being ranked in the low impact class and thus, this criterion should be maximized.

Three clearly defined classes were found (Palha et al., 2016): high impact activities $\left(C_{3}\right)$, medium impact activities $\left(C_{2}\right)$, and low impact activities $\left(C_{1}\right)$. It is expected that the activities sorted in each class will be managed according to their impact on the project, the risks involved, and the client's perceptions. High impact activities are costly, might be a specialized service, directly affect the schedule of the project and the client's perception of success, and have workers employed by the subcontractor working on the construction site. Medium impact activities may consist of long-term relations, have many available suppliers, suffer from delays that can be recovered by splitting the activity among different subcontractors, and strongly affect the client's satisfaction. Low impact activities can be handled more easily. Usually, these represent short-time relationships with lower costs, have a low impact on the client's satisfaction, and do not usually include workers' activities on the construction site. In this problem, since the DM is concerned about the impact of the activity on the project, it is assumed that the high impact class will have greater values and is the preferable class. The significance of this is that the activities sorted in this class will require more attention from the DM and are quite different from the ones sorted in the lower impact classes.

In order to calculate the limit profiles, the DM specified fictitious reference alternatives for each class. The cost was analyzed considering the governance model set between the contractor and the client while the other criteria were analyzed based on the DM's preferences. The scale constants were elicited by using the trade-off method. For the DC, exposure to risk was in the first position, because this could cause the contractor to have problems and could decrease the client's satisfaction. Cost was ranked second because this would certainly influence the client's perception and the profits of the project. Next was the expected duration because the contractor could not delay the project. The others were the available resources, the number of suppliers, interaction with other activities and, lastly, the need for maintenance. In addition, the function obtained in the elicitation process was linear for all criteria. Therefore, the value of the consequences of each activity in each criterion is presented in Table 3 and was calculated using a normalization procedure presented in Eqn (9) (de Almeida et al., 2015) in order to have all values on a scale $[0,1]$.

$$
v_{i}\left(x_{j}\right)=\left(x_{j i}-x_{\text {least }}\right) /\left(x_{\text {most }}-x_{\text {least }}\right),
$$

where $x_{j i}$ is the specific outcome of $x_{j}$ in criterion $i$; $x_{\text {most }}$ is the most preferred outcome found among the activities in criterion $i ; x_{\text {least }}$ is the least preferred outcome found among the activities in criterion $i$. 
Table 3. Normalized evaluation matrix of the activities considered

\begin{tabular}{|l|c|c|c|c|c|c|c|}
\hline \multirow{2}{*}{\multicolumn{1}{|c|}{ Description }} & \multicolumn{9}{c|}{ Criteria } & \multicolumn{7}{c|}{$g_{6}$} & $g_{7}$ \\
\cline { 2 - 8 } & $g_{1}$ & $g_{2}$ & $g_{3}$ & $g_{4}$ & $g_{5}$ & $g_{6}$ & 0.5000 \\
\hline Air conditioning & 0.0128 & 0.2416 & 0.2727 & 0.1667 & 0.5000 & 0.0000 & 0.000 \\
\hline Asphalt paving & 0.0178 & 0.0000 & 0.4545 & 0.0000 & 1.0000 & 1.0000 & 0.2500 \\
\hline Concrete & 1.0000 & 1.0000 & 0.1273 & 0.1667 & 1.0000 & 1.0000 & 1.0000 \\
\hline Concrete paving & 0.1711 & 0.1573 & 0.1818 & 1.0000 & 1.0000 & 1.0000 & 1.0000 \\
\hline Containers & 0.0882 & 1.0000 & 0.1273 & 1.0000 & 0.0000 & 0.0000 & 0.0000 \\
\hline Continuous flight auger (CFA) stake & 0.1711 & 0.4944 & 0.0000 & 1.0000 & 1.0000 & 1.0000 & 0.7500 \\
\hline Earthworks & 0.4474 & 0.2416 & 0.0909 & 0.0000 & 1.0000 & 1.0000 & 1.0000 \\
\hline Food supply & 0.2967 & 1.0000 & 0.1273 & 0.3750 & 0.5000 & 0.0000 & 0.5000 \\
\hline Gypsum liner & 0.0040 & 0.0478 & 0.4545 & 1.0000 & 1.0000 & 0.0000 & 0.2500 \\
\hline Heavy equipment & 0.0957 & 1.0000 & 0.0909 & 0.0625 & 0.5000 & 0.6667 & 1.0000 \\
\hline Hydroseeding & 0.0229 & 0.0309 & 0.4545 & 1.0000 & 1.0000 & 1.0000 & 0.2500 \\
\hline Molds, shoring and scaffolding & 0.0329 & 1.0000 & 0.1818 & 0.0625 & 1.0000 & 0.0000 & 1.0000 \\
\hline Precast concrete & 0.6734 & 0.7472 & 0.4545 & 0.0000 & 0.7500 & 0.0000 & 0.7500 \\
\hline Security of property & 0.1208 & 1.0000 & 0.1818 & 0.0000 & 0.5000 & 0.0000 & 0.5000 \\
\hline Transport of personnel & 0.3720 & 1.0000 & 0.1818 & 0.0000 & 0.5000 & 1.0000 & 0.5000 \\
\hline Suppression of vegetation & 0.0000 & 0.0309 & 1.0000 & 0.0000 & 1.0000 & 0.0000 & 0.7500 \\
\hline Waterproofing & 0.0015 & 0.1573 & 0.4545 & 0.0000 & 1.0000 & 0.0000 & 0.2500 \\
\hline
\end{tabular}

The DM had to consider the approach presented in the first step of the model to have the upper and lower thresholds elicited. By considering this preference information, the DM does not directly veto the activities but penalizes them in some criteria that he/she believes to have an unacceptable performance. For instance, if the cost of the activities varies strongly and could be compensated by the amount of time required to complete them, the DM could specify a lower threshold for cost, such that no activity that had a performance below it would have that criterion considered in its overall value. If he/she specified an upper threshold and the given activity had a performance between the upper and lower thresholds, then the criterion would be partially considered for inclusion in the calculation of the overall value of the activity. Finally, if the performance were above the upper threshold, then no penalty would be levied. Table 4 presents the upper and lower thresholds, the scale constants and the profiles of the classes.

The decision rules for veto, even though they can be classified in the two kinds of approaches, behave differently and have different meanings for the DM. The criterion veto index $\left(n c^{h}\right)$ is classified as the second approach, and when the DM decides to use it, it means that he/she will be comparing the activities not only with the class of analysis but also with classes below it. In this problem, the DM specified a criterion veto index of 1 , thus, $n c^{h}=1$, meaning that she only wants to compare the performance of the activity with the class immediately below it. In addition, for the $\mathrm{DM}$, it was not necessary to specify $\theta_{i}$, so it was set to zero.

The criterion weight coalition veto $\left(c^{h}\right)$ is classified in the first approach, and the DM's perception is no longer relative to the other classes. $\mathrm{He} / \mathrm{sh}$ e wants to analyze the performance of the activity only with the assignment class. The DM believes that if an activity has a performance which is at least as good within a small percentage of the one required for that class, the activity could be considered sufficient to fulfil the assignment. In this problem, the DM specified a criterion weight coalition veto of 0.5 , thus, $c^{h}=0.5$, meaning that when comparing the activity with the profiles, its performance is at least as good as that required in at least $50 \%$ of the criteria. In this problem, the DM wanted to be as restrictive as possible and decided to apply both decision rules for veto purposes. The results are presented below.

Table 4. Parameters from the DM

\begin{tabular}{|l|c|c|c|c|c|c|c|}
\hline \multirow{2}{*}{\multicolumn{1}{|c|}{ Parameters }} & \multicolumn{9}{c|}{ Criteria } \\
\cline { 2 - 8 } & $g_{1}$ & $g_{2}$ & $g_{3}$ & $g_{4}$ & $g_{5}$ & $g_{6}$ & $g_{7}$ \\
\hline Scale constants $\left(k_{i}\right)$ & 0.2276 & 0.1561 & 0.0728 & 0.1085 & 0.3704 & 0.0204 & 0.0442 \\
\hline Upper threshold $\left(u_{i}\right)$ & 400,000 & 50 & 10 & 5 & 2 & 2 & 2 \\
\hline Lower threshold $\left(l_{i}\right)$ & 220,000 & 20 & 10 & 5 & 2 & 2 & 2 \\
\hline$b_{2}$ & 600,000 & 21 & 5 & 4 & 3 & 2 & 2 \\
\hline$b_{3}$ & $1,200,000$ & 180 & 2 & 2 & 4 & 3 & 4 \\
\hline
\end{tabular}




\subsection{Discussion of results}

The results of this application are presented in Table 5. The findings were coherent with the DM's perception of the activities, most of which were sorted in the medium impact class. This behavior is compatible with what the DM expected regarding this problem since most of the activities should be long-term relationships with subcontractors that could be easily replaced whenever needed, or more than one subcontractor could be hired. Only two activities were sorted in the high impact activities: concrete and concrete paving. Both should be managed as high impact activities since the success of the project relies on the supply of concrete, and paving with concrete is a very demanding activity. Eleven activities were sorted in the medium impact class, and the DM felt comfortable with all of them, except for earthworks, which she thought could have been managed better if it had been classified as a high impact activity. This misclassification may have occurred because of missing criteria, such as evaluation of long-lasting impacts or quality requirements. The last four activities were sorted as low impact activities, and this was compatible with the DM's expectations.

It is important both to verify what the behavior of the model would be if the DM had decided to relax some of the parameters and also to compare results with those from SAW. It is important to realize that by relaxing all veto parameters, the additive-veto sorting approach would present the same results as in SAW. Therefore, Table 6 presents an analysis of the activities by considering this relaxation of parameters. When using SAW, none of the activities were assigned to the low impact class, which is compatible with the behavior mainly found in the construction indus-
Table 5. Results of the application

\begin{tabular}{|c|l|}
\hline Classes & \multicolumn{1}{c|}{ Activities } \\
\hline$C_{3}$ & Concrete; Concrete paving \\
\hline \multirow{3}{*}{$C_{2}$} & $\begin{array}{l}\text { Continuous flight auger stake; Earthworks; } \\
\text { Food supply; Gypsum liner; Heavy equipment; } \\
\text { Hydroseeding; Molds, shoring, and scaffolding; } \\
\end{array}$ \\
$\begin{array}{c}\text { Precast concrete; Security of property; } \\
\text { Transport of personnel; Waterproofing }\end{array}$ \\
\hline$C_{1}$ & $\begin{array}{l}\text { Air conditioning; Asphalt paving; Containers; } \\
\text { Suppression of vegetation }\end{array}$ \\
\hline
\end{tabular}

try, where DMs usually evaluate all activities as requiring attention compatible with the high or medium class, instead of considering which activities have a lesser impact and therefore can be evaluated more simply. This behavior makes the whole selection process more costly if it is considered that every activity requires all DMs to get involved in the selection process and that all subcontractors should be subjected to the same requirements. Under SAW, six of the 17 activities were assigned to the high impact class and eleven to the medium one, meaning that managing these contracts would require great effort and undertaking time-consuming procedures. By applying only the penalization, two of the activities previously classified as Class $C_{3}$ were vetoed and directed to Class $C_{2}$ : Molds, Shoring and Scaffolding; and Hydroseeding. In addition, both Containers and Air Conditioning (material and installation), which were previously sorted in Class $C_{2}$, were redirected to Class $C_{1}$. These results are compatible with the DM's perception regarding the impacts these activities may represent for the project.

Table 6. Analysis of the activities by applying different methods to the activities

\begin{tabular}{|l|c|c|c|c|c|c|}
\hline \multicolumn{1}{|c|}{ Activities } & $\begin{array}{c}\text { ROR-UTADIS } \\
\text { (Palha et al., 2016) }\end{array}$ & $\mathrm{SAW}$ & $\begin{array}{c}\text { Only } \\
\text { Penalization }\end{array}$ & $c_{q}$ & $n c_{q}$ & $n c_{q}$ and $c_{q}$ \\
\hline Concrete & $C_{3}$ & $C_{3}$ & $C_{3}$ & $C_{3}$ & $C_{3}$ & $C_{3}$ \\
\hline Concrete paving & $C_{3}$ & $C_{3}$ & $C_{3}$ & $C_{3}$ & $C_{3}$ & $C_{3}$ \\
\hline Continuous flight auger stake & $C_{3}$ & $C_{3}$ & $C_{3}$ & $C_{3}$ & $C_{2}$ & $C_{2}$ \\
\hline Precast Concrete & $C_{2}$ & $C_{3}$ & $C_{3}$ & $C_{3}$ & $C_{2}$ & $C_{2}$ \\
\hline Molds, shoring, and scaffolding & $C_{2}$ & $C_{3}$ & $C_{2}$ & $C_{2}$ & $C_{2}$ & $C_{2}$ \\
\hline Hydroseeding & $C_{3}$ & $C_{3}$ & $C_{2}$ & $C_{2}$ & $C_{2}$ & $C_{2}$ \\
\hline Earthworks & $C_{3}$ & $C_{2}$ & $C_{2}$ & $C_{2}$ & $C_{2}$ & $C_{2}$ \\
\hline Food supply & $C_{2}$ & $C_{2}$ & $C_{2}$ & $C_{2}$ & $C_{2}$ & $C_{2}$ \\
\hline Gypsum liner & $C_{2}$ & $C_{2}$ & $C_{2}$ & $C_{2}$ & $C_{2}$ & $C_{2}$ \\
\hline Heavy equipment & $C_{2}$ & $C_{2}$ & $C_{2}$ & $C_{2}$ & $C_{2}$ & $C_{2}$ \\
\hline Security of property & $C_{1}$ & $C_{2}$ & $C_{2}$ & $C_{2}$ & $C_{2}$ & $C_{2}$ \\
\hline Transport of personnel & $C_{2}$ & $C_{2}$ & $C_{2}$ & $C_{2}$ & $C_{2}$ & $C_{2}$ \\
\hline Waterproofing & $C_{1}$ & $C_{2}$ & $C_{2}$ & $C_{2}$ & $C_{2}$ & $C_{2}$ \\
\hline Asphalt paving & $C_{1}$ & $C_{2}$ & $C_{2}$ & $C_{1}$ & $C_{2}$ & $C_{1}$ \\
\hline Suppression of vegetation & $C_{1}$ & $C_{2}$ & $C_{2}$ & $C_{1}$ & $C_{2}$ & $C_{1}$ \\
\hline Air conditioning & $C_{1}$ & $C_{2}$ & $C_{1}$ & $C_{1}$ & $C_{1}$ & $C_{1}$ \\
\hline Containers & $C_{1}$ & $C_{2}$ & $C_{1}$ & $C_{1}$ & $C_{1}$ & $C_{1}$ \\
\hline
\end{tabular}


The use of the criterion veto index was more restrictive than considering only the penalization by directing two activities to Class $C_{2}$ : CFA Stake, and Precast concrete. This evaluation is compatible with the impacts these activities may have on this project. Using the criterion weight coalition veto only moved Suppression of vegetation and Asphalt paving from Class $C_{2}$ to Class $C_{1}$. The result is coherent with these activities and their impact on the project. When analyzing the use of both conditions, their impact together is much more restrictive than applying each of them individually, thereby keeping the activities in the lowest possible classes of assignment.

The additive-veto sorting approach can be better appreciated when it is applied to this problem. The parameters are intuitive, and the DM can specify the required information without prior knowledge of exemplary alternatives. The results are coherent with the DM's preference structure, and the veto conditions corrected several misclassification errors. When compared to the results presented by Palha et al. (2016), which used the holistic method ROR-UTADIS (Kadziński et al., 2015), one finds that most of the activities were assigned to the same class. However, some differences regarding the input information and the results can be found.

Before becoming a DC in the construction of this brewery, this DM worked as a Project Manager in the construction of a railway with $1,200 \mathrm{~km}$ of extension which cost US\$1,750 million. Therefore, some bias was brought from the previous contract into this analysis. This can be verified by observing services such as Earthwork and CFA Stake, which were assigned as exemplary alternatives in Palha et al. (2016) into class $C_{3}$. When using the additiveveto sorting approach, the first activity did not have an overall value compatible with class $C_{3}$. Whereas the overall value of the second activity was higher than that required to belong to class $C_{3}$, but 12 firms could execute the activity, and it had an estimated cost of US\$ 700,000.00, which made it incompatible with the profile of class $C_{3}$. Therefore, they were sorted into class $C_{2}$. Also, in Palha et al. (2016) it was verified that the DM did not agree with the classification of the Hydroseeding because it was incompatible with the impact it could have on the project, a problem that was solved by using the additive-veto sorting approach.

A sensitivity analysis was carried out considering the parameters in which there could be any degree of hesitation or uncertainty, such as weights and the criterion weight coalition veto $\left(c^{h}\right)$. Parameters that have been defined based on technical aspects have not been considered in this sensitivity analysis, for instance, the upper and lower thresholds. Table 7 presents the alternatives that would change classes when each parameter was modified.

It is possible to verify in Table 7 that Suppression of Vegetation changed classes when $c^{h}$ or the weights of criterion $g_{1}$ were decreased by $10-20 \%$, when the weight of criterion $g_{2}$ was decreased by $15-20 \%$ or when the weight of criterion $g_{5}$ was increased by $10-20 \%$. This activity, which was sorted in class $C_{1}$ when considering the parameters elicited from the DM, changed to class $C_{2}$ during the sensitivity analysis. Table 6 showed that $c^{h}$ directed this alternative to class $C_{1}$ because it had a bad performance in criteria $g_{1}, g_{2}, g_{4}$, and $g_{6}$, which together represent $51.26 \%$ of the weights. In addition, it can be seen from Table 3 that this alternative has the maximum possible performance in criterion $g_{5}$, which has the maximum weight in the original weight vector (Table 4). Thus, when it is increased, the overall value of this alternative increases and it is sorted in a higher class. Asphalt Paving also changed classes in a situation opposite to the one verified for the Suppression of vegetation. It was sorted in class $C_{2}$ but dropped to class $C_{1}$ when $c^{h}$ or the weights of criteria $g_{1}$ and $g_{2}$ were

Table 7. Sensitivity analysis

\begin{tabular}{|c|c|c|c|c|c|c|}
\hline Variables & $-20 \%$ & $-15 \%$ & $-10 \%$ & $+10 \%$ & $+15 \%$ & $+20 \%$ \\
\hline$g_{1}$ & $\begin{array}{l}\text { Suppression of } \\
\text { vegetation: } \\
C_{1} \rightarrow C_{2}\end{array}$ & $\begin{array}{l}\text { Suppression of } \\
\text { vegetation: } \\
C_{1} \rightarrow C_{2} \\
\end{array}$ & $\begin{array}{l}\text { Suppression of } \\
\text { vegetation: } \\
C_{1} \rightarrow C_{2} \\
\end{array}$ & $\begin{array}{l}\text { Asphalt paving: } \\
C_{2} \rightarrow C_{1}\end{array}$ & $\begin{array}{l}\text { Asphalt paving: } \\
C_{2} \rightarrow C_{1}\end{array}$ & $\begin{array}{l}\text { Asphalt paving: } \\
C_{2} \rightarrow C_{1}\end{array}$ \\
\hline$g_{2}$ & $\begin{array}{l}\text { Suppression of } \\
\text { Vegetation: } \\
C_{1} \rightarrow C_{2}\end{array}$ & $\begin{array}{l}\text { Suppression of } \\
\text { Vegetation: } \\
C_{1} \rightarrow C_{2}\end{array}$ & - & $\begin{array}{l}\text { Asphalt paving: } \\
C_{2} \rightarrow C_{1}\end{array}$ & $\begin{array}{l}\text { Asphalt paving: } \\
C_{2} \rightarrow C_{1}\end{array}$ & $\begin{array}{l}\text { Asphalt paving: } \\
C_{2} \rightarrow C_{1}\end{array}$ \\
\hline$g_{3}$ & - & - & - & - & - & - \\
\hline$g_{4}$ & - & - & - & - & $\begin{array}{l}\text { Asphalt paving: } \\
C_{2} \rightarrow C_{1}\end{array}$ & $\begin{array}{l}\text { Asphalt paving: } \\
C_{2} \rightarrow C_{1}\end{array}$ \\
\hline$g_{5}$ & $\begin{array}{l}\text { Asphalt paving: } \\
C_{2} \rightarrow C_{1} \\
\text { Concrete paving: } \\
C_{3} \rightarrow C_{2}\end{array}$ & $\begin{array}{l}\text { Asphalt paving: } \\
C_{2} \rightarrow C_{1}\end{array}$ & $\begin{array}{l}\text { Asphalt paving: } \\
C_{2} \rightarrow C_{1}\end{array}$ & $\begin{array}{l}\text { Suppression of } \\
\text { vegetation: } \\
C_{1} \rightarrow C_{2}\end{array}$ & $\begin{array}{l}\text { Suppression of } \\
\text { vegetation: } \\
C_{2} \rightarrow C_{1}\end{array}$ & $\begin{array}{l}\text { Suppression of } \\
\text { vegetation: } \\
C_{2} \rightarrow C_{1}\end{array}$ \\
\hline$g_{6}$ & - & - & - & - & - & - \\
\hline$g_{7}$ & - & - & - & - & - & - \\
\hline$c^{h}$ & $\begin{array}{l}\text { Suppression of } \\
\text { vegetation: } \\
C_{1} \rightarrow C_{2}\end{array}$ & $\begin{array}{l}\text { Suppression of } \\
\text { vegetation: } \\
C_{1} \rightarrow C_{2}\end{array}$ & $\begin{array}{l}\text { Suppression of } \\
\text { vegetation: } \\
C_{1} \rightarrow C_{2}\end{array}$ & $\begin{array}{l}\text { Asphalt paving: } \\
\mathrm{C}_{2} \rightarrow \mathrm{C}_{1} \\
\text { Concrete paving: } \\
\mathrm{C}_{3} \rightarrow \mathrm{C}_{2}\end{array}$ & $\begin{array}{l}\text { Asphalt paving: } \\
\mathrm{C}_{2} \rightarrow \mathrm{C}_{1} \\
\text { Concrete paving: } \\
\mathrm{C}_{3} \rightarrow \mathrm{C}_{2}\end{array}$ & $\begin{array}{l}\text { Asphalt paving: } \\
\mathrm{C}_{2} \rightarrow \mathrm{C}_{1} \\
\text { Concrete paving: } \\
\mathrm{C}_{3} \rightarrow \mathrm{C}_{2}\end{array}$ \\
\hline
\end{tabular}


increased by $10-20 \%$, when the weight of criterion $g_{5}$ was decreased by $10-20 \%$ or when the weight of criterion $g_{4}$ was increased by $15-20 \%$. Tables 3 and 6 show that Asphalt paving has a condition similar to that of Suppression of vegetation.

Finally, only one alternative which had been sorted in class $C_{3}$ was directed to a lower class during the sensitivity analysis, namely, Concrete Paving when $c^{h}$ became too restrictive. By increasing this value to $20 \%$, it became 0.6 . Thus, the DM verified that using a criterion weight coalition veto of 0.5 was appropriate according to her preferences. The sensitivity analysis is important to aid the DM to feel comfortable about the parameters provided and to be aware of any possible inconsistency.

Uncertainty may appear in such problems when defining parameters for the decision model and also in the scores defined for evaluating the performance of the alternatives within each criterion. To avoid unnecessary modelling costs, when sensitivity analysis shows that part of the information used in the decision process may change the results considerably, such a sensitive piece of information is explored so the uncertainty in its value may be reduced. Multiattribute Utility Theory is often used to model probabilistic consequences with a similar elicitation process (Keeney \& Raiffa, 1993). For such cases, Bregar (2018) has verified the impact of a veto component on the DM's behavior with regard to risk (prone or risk-averse).

\subsection{Managerial impacts}

Besides the benefits of improving this managerial decision process, there is the possibility of reducing the costs associated with spending too much effort and time on the hiring procedures of activities that do not represent risks to the contractor. One possible approach is to sort the activities into classes in order to allow them to be dealt with in a more compatible way by using a selection process and contract management approach that are based on the impact that the activities are expected to have on the project, as discussed in Palha et al. (2016). By dividing activities into classes, the analyst could use different procedures for each class, which are consistent with the impact of the activity on the project. In addition, this process allows DMs, such as the DC, to delegate responsibility and power to mid-level managers, by identifying the less critical activities that the latter may handle themselves. This categorization could be structured by using a sorting procedure that reflects preference levels.

The hiring process, as well as the management of the contract, might be tackled differently depending on the impact that this may have on the project and the contractor. Usually, the negotiation process in each class will be undertaken differently because more DMs are involved in the higher impact classes compared to the lower ones. Thus, the main objective of proposing a model to sort the activities into classes before conducting a selection procedure is to improve the decision process by decreasing the risk of liabilities during the project. Thus, DMs need not get involved in every single bidding procedure, thereby saving valuable time. Moreover, money can be saved since the requirements for lower impact activities are not as strict as they are for higher ones. By concentrating on reducing risk and liability at a higher level, the contractor can make more realistic and wiser decisions. In addition, it might be possible to avoid situations in which problems were overlooked because the decision was made without having a rigorous framework.

The results show that when using SAW to sort the activities into classes, management might require more effort and time from DMs because most of the activities are sorted into the high impact activities class, and none of the activities is sorted into the low impact class. This nuance prompts all DMs to get involved in selecting subcontractors which is more demanding when bidders are being selected. This behavior is usually found in the professional context, which prompts DMs to realize that some activities considered as belonging to the high impact class could be managed as belonging to the medium impact class and, likewise, activities assigned to the medium impact class could be managed as belonging to the low impact class. However, unless DMs have the support of an analytical tool, they not feel comfortable about assigning these activities to more compatible classes, because as they do not have enough knowledge about the context found in that project, this leads to conservative decision-making, thus making the whole selection process more costly than necessary. Also, contractors do not include these costs in the cost estimation of the project.

The proposed model provides DMs with valuable guidance on managing subcontractors and how to do so more realistically, thereby reducing not only the costs associated with these contracts, the liabilities and the risks involved in conducting the activity but also their negative impacts on other activities and workers. In addition, the DMs can easily understand the parameters, because they are used to making trade-offs and they intuitively use the veto component. Thus, it does not take more than two hours from the DC to evaluate the whole process. And only the DC, who is the person responsible for the success of the project, is involved in this analysis. Another gain regarding the managerial benefits of using this approach is that now there is a structured decision process which can be audited and revised if any inconsistencies should be found. Now, if $20 \%$ of the alternatives of the case study are assigned to class $C_{1}$, this implies that the time that the DMs involved in the project would have devoted to these is saved and can be redeployed to other activities. This amount of time is far greater than the two hours that were needed to evaluate the entire elicitation process in the case study. Thus, DMs can use their knowledge to favor the project and make decisions that are better informed.

\section{Conclusions and future works}

A case study prompted the proposition of a new quasicompensatory sorting approach to tackle the decision- 
making process for an important civil engineering project, which lasted for 3 years. Although, this problem is faced by all main contractors independently of the country in which a project is being conducted, the case study was conducted in one of the biggest contractors in Brazil.

The construction industry may well improve the management of its subcontractors by using this model to sort activities prior to bidding, thereby avoiding unnecessary managerial efforts that arise from taking excessive riskaverse precautions. Therefore, a new MCDM method was proposed in this paper which has important impacts on the management of heavy construction civil engineering projects. The approach used in this paper for sorting subcontractors' activities in construction projects can be applied to any heavy construction project. This can be done easily, simply by adjusting parameters according to the particularities and priorities of a given project. The new procedure allows the specificities of activities to be taken into consideration in order to avoid biased assignments.

Based on the aspects of this MCDM approach, the characteristics of the civil engineering environment and the case study, the main conclusions can be summarized as follows:

1. The "quasi-compensatory" parameters proposed in this model are important to avoid alternatives being sorted in classes that are not compatible with their impact on the construction project, as was verified in the sensitivity analysis.

2. It is important to note that some difficulties might arise during the preference elicitation. Therefore, the whole process relies on how skilful the analyst is at conducting the interview and on making the computer tool easy to use. Otherwise, the DM might provide pieces of preference information that will not lead the model to produce a recommendation that is compatible with his/her preferences. Examples of these are: thresholds that lead to one class not being assigned with any activities; instead of making trade-offs among criteria, they are evaluated based on their "importance" which is something that is incompatible with the additive model; or veto indices are provided that do not reflect the $\mathrm{DM}^{\prime}$ 's preferences because they are too restrictive or because these indices have been disabled.

3. In addition, it is mandatory to inform the DM about the impact that such a process might have on the project. Otherwise, he/she might define the classes in a way that will not only give rise to problems that are greater than those associated with the costs of selection but also might adversely affect the performance of the contractor with regard to his/her relationship with the owner.

4. At last, in the case of group decision-making, the facilitator may guide the DMs to a consensus in terms of parameters or consider deploying a voting procedure. If the voting procedure results on conflicting recommendations the parameters can be aggregated by considering the weight each DM represent to the problem.

In future research studies, it is suggested that the model be applied generally in other fields to other types of sorting problems. It should be considered as a model on how to manage each of the classes and how the negotiation process might be driven by these scenarios. In addition, subcontractor selection may be enhanced by considering simulation and optimization techniques (Raoufi, Seresht, \& Fayek, 2017) associated with an agent based mediation process (Palha, 2019).

\section{Acknowledgements}

The authors are grateful to the Brazilian Research Council (CNPq) for the funding received to support the research contained in this paper.

\section{Funding}

The authors are grateful to the Brazilian Research Council (CNPq) for the funding received to support the research contained in this paper.

\section{Author contributions}

RPP, ATA, and KWH were responsible for conceptualization, methodological development and writing (original manuscript), RPP was responsible for data collection, and analysis; RPP and KWH were responsible for manuscript revisions, RPP, ATA, DCM, and KWH were involved in the validation. ATA and DCM were responsible for supervising RPP's PhD thesis.

\section{Disclosure statement}

The authors declare that there is no conflict of interests regarding the publication of this paper.

\section{References}

Abbasianjahromi, H., Rajaie, H., \& Shakeri, E. (2013). A framework for subcontractor selection in the construction industry. Journal of Civil Engineering and Management, 19(2), 158-168. https://doi.org/10.3846/13923730.2012.743922

Abbasianjahromi, H., Rajaie, H., Shakeri, E., \& Kazemi, O. (2016). A new approach for subcontractor selection in the construction industry based on portfolio theory. Journal of Civil Engineering and Management, 22(3), 346-356. https://doi.org/10.3846/13923730.2014.897983

Aguayo, E. A., Mateos, A., \& Jiménez, A. (2014). A new dominance intensity method to deal with ordinal information about a DM's preferences within MAVT. Knowledge-Based Systems, 69(1), 159-169. https://doi.org/10.1016/j.knosys.2014.05.017

Araz, C., \& Ozkarahan, I. (2007). Supplier evaluation and management system for strategic sourcing based on a new multicriteria sorting procedure. International Journal of Production Economics, 106(2), 585-606.

https://doi.org/10.1016/j.ijpe.2006.08.008 
Arditi, D., \& Chotibhongs, R. (2005). Issues in subcontracting practice. Journal of Construction Engineering and Management, 131(8), 866-876. https://doi.org/10.1061/(ASCE)0733-9364(2005)131:8(866)

Ballesteros-Perez, P., Skitmore, M., Pellicer, E., \& Zhang, X. L. (2016). Scoring rules and competitive behavior in best-value construction auctions. Journal of Construction Engineering and Management, 142(9), 14. https://doi.org/10.1061/(ASCE)CO.1943-7862.0001144

Biruk, S., Jaśkowski, P., \& Czarnigowska, A. (2017). Minimizing project cost by integrating subcontractor selection decisions with scheduling. IOP Conference Series: Materials Science and Engineering, 245, 072007.

https://doi.org/10.1088/1757-899X/245/7/072007

Bregar, A. (2018). Decision support on the basis of utility models with discordance-related preferential information: investigation of risk aversion properties. Journal of Decision Systems, 27, 236-243. https://doi.org/10.1080/12460125.2018.1468170

de Almeida, A. T. (2013). Additive-veto models for choice and ranking multicriteria decision problems. Asia-Pacific Journal of Operational Research, 30(6), 1.

https://doi.org/10.1142/S0217595913500267

de Almeida, A. T., Cavalcante, C. A. V., Alencar, M. H., Ferreira, R. J. P., de Almeida-Filho, A. T., \& Garcez, T. V. (2015). Multicriteria and multiobjective models for risk, reliability and maintenance decision analysis. International series in operations research and management science ( $1^{\text {st }}$ ed., Vol. 231). Cham: Springer International Publishing. https://doi.org/10.1007/978-3-319-17969-8

Doumpos, M., \& Zopounidis, C. (2004). Multicriteria decision aid classification methods. In P. M. Pardalos \& D. Hearn (Eds.), Applied Optimization (Vol. 73). Boston: Kluwer Academic Publishers. https://doi.org/10.1007/b101986

Filzmoser, M., \& Gettinger, J. (2013). Negotiation by veto. In B. Martinovski (Ed.). $13^{\text {th }}$ International Meeting on Group Decision and Negotiation (pp. 348-350). Stockholm.

Fishburn, P. C. (1976). Noncompensatory preferences. Synthese, 33(1), 393-403. https://doi.org/10.1007/BF00485453

Holt, G. D., Olomolaiye, P. O., \& Harris, F. C. (1994). Evaluating prequalification criteria in contractor selection. Building and Environment, 29(4), 437-448. https://doi.org/10.1016/0360-1323(94)90003-5

Holt, G. D., Olomolaiye, P. O., \& Harris, F. C. (1995). A review of contractor selection practice in the U.K. construction industry. Building and Environment, 30(4), 553-561.

https://doi.org/10.1016/0360-1323(95)00008-T

Iooss, B., \& Lemaître, P. (2015). A review on global sensitivity analysis methods. In G. Dellino \& C. Meloni (Eds.). Uncertainty management in simulation-optimization of complex systems (Vol. 59, pp. 101-122). Boston: Springer. https://doi.org/10.1007/978-1-4899-7547-8_5

Ishizaka, A., Pearman, C., \& Nemery, P. (2012). AHPSort: an AHP-based method for sorting problems. International Journal of Production Research, 50(17), 4767-4784. https://doi.org/10.1080/00207543.2012.657966

Kadziński, M., Ciomek, K., \& Słowiński, R. (2015). Modeling assignment-based pairwise comparisons within integrated framework for value-driven multiple criteria sorting. European Journal of Operational Research, 241(3), 830-841. https://doi.org/10.1016/j.ejor.2014.09.050

Keeney, R. L., \& Raiffa, H. (1993). Decision with multiple objectives: preferences and value trade-offs. New York: Cambridge University Press. https://doi.org/10.1017/CBO9781139174084
Kelemenis, A., \& Askounis, D. (2010). A new TOPSIS-based multi-criteria approach to personnel selection. Expert Systems with Applications, 37(7), 4999-5008. https://doi.org/10.1016/j.eswa.2009.12.013

Keshavarz Ghorabaee, M., Amiri, M., Salehi Sadaghiani, J., \& Hassani Goodarzi, G. (2014). Multiple criteria group decision-making for supplier selection based on COPRAS method with interval type-2 fuzzy sets. International Journal of Advanced Manufacturing Technology, 75(5-8), 1115-1130. https://doi.org/10.1007/s00170-014-6142-7

Kumaraswamy, M. M., \& Matthews, J. D. (2000). Improved subcontractor selection employing partnering principles. Journal of Management in Engineering, 16(3), 47-57. https://doi.org/10.1061/(ASCE)0742-597X(2000)16:3(47)

Love, P. E. D., Edwards, D. J., Smith, J., \& Walker, D. H. T. (2009). Divergence or congruence? A path model of rework for building and civil engineering projects. Journal of Performance of Constructed Facilities, 23(6), 480-488. https://doi.org/10.1061/(ASCE)CF.1943-5509.0000054

Martel, J.-M., \& Matarazzo, B. (2016). Other outranking approaches. In Multiple criteria decision analysis: State of the art surveys (pp. 221-282). New York: Springer Science + Business Media. https://doi.org/10.1007/978-1-4939-3094-4_7

Medeiros, C. P., Alencar, M. H., \& de Almeida, A. T. (2017). Multidimensional risk evaluation of natural gas pipelines based on a multicriteria decision model using visualization tools and statistical tests for global sensitivity analysis. Reliability Engineering and System Safety, 165, 268-276.

https://doi.org/10.1016/j.ress.2017.04.002

Moulin, H. (1981). The proportional veto principle. The Review of Economic Studies, 48(3), 407-416. https://doi.org/10.2307/2297154

Munda, G. (2016). Multiple criteria decision analysis and sustainable development. In S. Greco, M. Ehrgott, \& J. Figueira (Eds.), Multiple criteria decision analysis. International Series in Operations Research \& Management Science (Vol. 233, pp. 1235-1267). New York: Springer. https://doi.org/10.1007/978-1-4939-3094-4_27

Mungle, S., Benyoucef, L., Son, Y. J., \& Tiwari, M. K. (2013). A fuzzy clustering-based genetic algorithm approach for timecost-quality trade-off problems: A case study of highway construction project. Engineering Applications of Artificial Intelligence, 26(8), 1953-1966. https://doi.org/10.1016/j.engappai.2013.05.006

Ng, S. T., \& Skitmore, M. (2014). Developing a framework for subcontractor appraisal using a balanced scorecard. Journal of Civil Engineering and Management, 20(2), 149-158. https://doi.org/10.3846/13923730.2013.802705

Palha, R. P. (2019). Negotiation throughout flexible and interactive tradeoffs applied to construction procurement. Automation in Construction, 99, 39-51. https://doi.org/10.1016/j.autcon.2018.12.002

Palha, R. P., de Almeida, A. T., \& Alencar, L. H. (2016). A model for sorting activities to be outsourced in civil construction based on ROR-UTADIS. Mathematical Problems in Engineering, ID 9236414, 1-15. https://doi.org/10.1155/2016/9236414

Polat, G. (2016). Subcontractor selection using the integration of the AHP and PROMETHEE methods. Journal of Civil Engineering and Management, 22(8), 1042-1054. https://doi.org/10.3846/13923730.2014.948910

Raoufi, M., Seresht, N. G., \& Fayek, A. R. (2017). Overview of fuzzy simulation techniques in construction engineering and management. In 2016 Annual Conference of the North Ameri- 
can Fuzzy Information Processing Society (NAFIPS), El Paso, TX, USA. https://doi.org/10.1109/NAFIPS.2016.7851610

Roszkowska, E., \& Wachowicz, T. (2015). Application of fuzzy TOPSIS to scoring the negotiation offers in ill-structured negotiation problems. European Journal of Operational Research, 242(3), 920-932. https://doi.org/10.1016/j.ejor.2014.10.050

Roy, B., \& Bouyssou, D. (1993). Aide multicritère à la decision: méthodes et cas. Paris: Economica.

Sabio, P., Jiménez-Martín, A., \& Mateos, A. (2015). Veto values within MAUT for group decision making on the basis of dominance measuring methods with fuzzy weights. In B. Kamiski, G. E. Kersten, \& T. Wachowicz (Eds.), Oultooks and insights on group decision and negotiation (pp. 119-130). Warsaw: Springer International Publishing. https://doi.org/10.1007/978-3-319-19515-5_10

Sabokbar, H. F., Hosseini, A., Banaitis, A., \& Banaitiene, N. (2016). A novel sorting method topsis-sort: An application for Tehran environmental quality evaluation. E a M: Ekonomie a Management, 19(2), 87-104.

https://doi.org/10.15240/tul/001/2016-2-006

Schöttle, A., \& Arroyo, P. (2017). Comparison of weightingrating-calculating, best value, and choosing by advantages for bidder selection. Journal of Construction Engineering and Management, 143(8), 05017015. https://doi.org/10.1061/(ASCE)CO.1943-7862.0001342

Singh, D., \& Tiong, R. (2005). A fuzzy decision framework for contractor selection. Journal of Construction Engineering and Management, 131(1), 62-70.

https://doi.org/10.1061/(ASCE)0733-9364(2005)131:1(62)
Sönmez, M., Holt, G. D., Yang, J. B., \& Graham, G. (2002). Applying evidential reasoning to prequalifying construction contractors. Journal of Management in Engineering, 18(3), 111-119. https://doi.org/10.1061/(ASCE)0742$597 X(2002) 18: 3(111)$

Tan, Y., Xue, B., \& Cheung, Y. T. (2017). Relationships between main contractors and subcontractors and their impacts on main contractor competitiveness: An empirical study in Hong Kong. Journal of Construction Engineering and Management, 143(7), 05017007. https://doi.org/10.1061/(ASCE)CO.1943-7862.0001311

Ulubeyli, S., Manisali, E., \& Kazaz, A. (2010). Subcontractor selection practices in international construction projects. Journal of Civil Engineering and Management, 16(1), 47-56. https://doi.org/10.3846/jcem.2010.04

Vetschera, R., Chen, Y., Hipel, K. W., \& Kilgour, D. M. (2010). Robustness and information levels in case-based multiple criteria sorting. European Journal of Operational Research, 202(3), 841-852. https://doi.org/10.1016/j.ejor.2009.06.026

Wachowicz, T., \& Blaszczyk, P. (2013). TOPSIS based approach to scoring negotiating offers in negotiation support systems. Group Decision and Negotiation, 22(6), 1021-1050. https://doi.org/10.1007/s10726-012-9299-1

Wan, S. P., \& Li, D. F. (2013). Fuzzy LINMAP approach to heterogeneous MADM considering comparisons of alternatives with hesitation degrees. Omega, 41(6), 925-940. https://doi.org/10.1016/j.omega.2012.12.002

Zopounidis, C., \& Doumpos, M. (2002). Multicriteria classification and sorting methods: A literature review. European Journal of Operational Research, 138(2), 229-246. https://doi.org/10.1016/S0377-2217(01)00243-0 